\title{
Madachironomus, a new genus of tribe Pseudochironomini (Diptera: Chironomidae, Chironominae) from Madagascar
}

\author{
Trond Andersen \\ ${ }^{1}$ Department of Natural History, University Museum of Bergen, University of Bergen, P.O. Box 7800, \\ N-5020 Bergen, Norway. E-mail: trond.andersen@uib.no \\ http://zoobank.org/9B1973A5-5807-48C0-8942-2AD139F91232
}

\begin{abstract}
Madachironomus gen. $\mathrm{n}$. is described based on male and female imagines collected at two watersheds in Madagascar. Two species are included, M. lakazana sp. n. from Lakazana River, Antananarivo province and $M$. rongaronga $\mathrm{sp}$. n. from Rongaronga River, Toamasina province. The adults have a black comb on the apex of the fore tibia, similar to the combs on mid- and hind tibiae, thus placing the new genus in the tribe Pseudochironomini Sæther. The male has a strong, moderately long, nearly parallel-sided anal point with broadly rounded apex, without microtrichia except at base, and a digitiform, apically split median volsella with strong brush-like setae, projecting medially. The female sternite VIII has a very dense posteromedial to posterolateral field of setae, the gonocoxapodeme VIII is nearly straight, the gonapophysis VIII has closely adjacent, indistinctly separable lobes; the ovoid seminal capsules have nearly straight spermathecal ducts and the labia have internal apodemes and spinose chaetulae on dorsomedial surfaces.
\end{abstract}

\section{Introduction}

The tribe Pseudochironomini within the subfamily Chironomini was established by Sæther (1977a: 154). The tribe is characterized by having a black comb on apex of fore tibia, similar to the combs on mid- and hind tibiae, and in the male the median volsella is generally present. Originally the genera Aedokritus Roback, 1958, Manoa Fittkau, 1963, Megacentron Freeman, 1961, Pseudochironomus Malloch, 1915, Psilochironomus Sublette, 1966, and Riethia Kieffer, 1917 were included in the tribe.

The genus Aedokritus was erected by Roback (1958); at present six described species distributed in South America are included (Trivinho-Strixino 1997). The genus Manoa was erected for M. $o b$ scura Fittkau, 1963, from the Amazon State in Brazil (Fittkau 1963). Later, M. tangae Andersen \& Sæther, 1997, from Tanzania, East Africa and
M. pahayokeensis Jacobsen, 2002, from Florida, U.S.A and the Dominican Republic were described and a new species has also been found in Oriental China (Andersen \& Sæther 1997; Jacobsen \& Perry 2002; da Silva et al. 2015; Xiaolong Lin pers. com.). The genus Megacentron was erected based on M. erebeum (Skuse, 1889) from Victoria in Australia by Freeman (1961); later M. cuneicalcar (Edwards, 1931) from Argentina and Chile was included. The genus Pseudochironomus, described by Malloch (1915), with 11 species in the Nearctic region, one species in the Palaearctic region and several, mainly undescribed species in the Neotropical region is the most species rich genus in the tribe; the Nearctic species were reviewed by Sæther (1977b). The genus Riethia was erected by Kieffer (1917); at present five species distributed in the Australian and Neotropical regions are included (Trivinho-Strixinho et al. 2009).

The genus Psilochironomus was established by Sublette (1966) based on Chironomus fumeus Walley, 1934, from Guyana. Chironomus fumeus was described by Walley (in Curran 1934) from a single, incompletely preserved adult male and the brief description and sketchy drawing (Walley in Curran 1934: fig. 18) give no indication of any gonocoxite appendages. Sublette (1966) examined and redescribed the pinned remains of the holotype and reported that the genitalia were missing. Nevertheless, he proposed the new genus Psilochironomus, with P. fumeus (Walley) as the only member, stating that the genus "may be distinguished ... by the genitalia lacking superior and inferior appendages." However, today both Chironomus fumeus and Psilochironomus are considered to be nomina dubia in Pseudochironomini (see Spies \& Reiss 1996: 90).

Below two new species from Madagascar are described, figured and placed in a new genus of the tribe Pseudochironomini. Both species have a black comb on the apex of the fore tibia, similar to the combs on mid- and hind tibiae, and the male has a digitiform, apically split median volsella with strong brush-like setae. 


\section{Material and Methods}

Molecular extraction for sequencing yielded no productive results, presumably due to the preservation (denatured alcohol) and age of the specimens. Prior to examination the specimens were mounted in Canada balsam following the procedure outlined by Sæther (1969). Morphological terminology follows Sæther (1980). Coloration is based on alcohol-preserved specimens. Measurements are given as ranges, followed by the mean when four or more specimens were measured, followed by the number of specimens measured in parentheses.

The holotypes and most paratypes will be deposited in the Zoologische Staatssammlung München, Munich, Germany (ZSM); the remaining paratypes will be kept in the Department of Natural History (ZMBN), Bergen University Museum, Norway.

\section{Madachironomus new genus}

http://zoobank.org/40BE526D-5658-4CEA-83C9186057B84F12

Type species: Madachironomus lakazana sp. n.

Other included species: Madachironomus rongaronga $\mathrm{sp} . \mathrm{n}$.

Etymology: The name of the new genus is a combination of the first two syllables from the place name Madagascar using the suffix -chironomus.

\section{Generic diagnosis}

The adults have the fore tibiae with one spurred comb, mid- and hind tibiae each with two separate, spurred combs; all combs subtriangular with rather steep flanks, the 1-2 pairs of teeth flanking the spur arising from the base of the latter and farther distally than the other comb teeth. The male has a strong, moderately long, nearly parallel-sided anal point with broadly rounded apex, without microtrichia except at base, and a digitiform, apically split median volsella with strong brush-like setae. The female has sternite VIII with a very dense posteromedial to posterolateral field of setae, a nearly straight gonocoxapodeme VIII, gonapophysis VIII with closely adjacent, indistinctly separable lobes, ovoid seminal capsules with nearly straight spermathecal ducts and labium with internal apodeme and spinose chaetulae on dorsomedial surfaces.

\section{Generic description}

Adult male

Antenna. With 13 flagellomeres, AR about 2.4.

Head. Frontal tubercles absent. Temporal setae consisting of inseparably intergrading verticals and postorbitals, briefly bi- to tri-serial near transition of eye to its dorsomedial extension. Eye bare; dorsomedial eye extension parallel-sided, about 2.5 times as wide as high, mostly of 5 facets per diagonal; interocular distance in frontal view about 3 times the apical width of the extension, slightly lower dorsally than ventrally. Clypeus with numerous setae arising over nearly entire surface. Palp 5-segmented, palpomere 3 with 2-3 sensilla clavata apically.

Thorax. Not projecting anterodorsally or arching overhead; scutal tubercle absent. Antepronotum visible in dorsal view, medially with relatively narrow but deep V-shaped notch, each lobe narrowest in mid-section; in lateral view with dorsal projection to anterior and with curved subsurface contour indicating the anteromedial excavation; with dorsal and ventrolateral semi-spinose, short setae. Acrostichals weak, numerous, paired or interspersed with small, light spots without alveoli or setae; setae short, semi-spinose, occurring from near antepronotum to almost as far posterior as dorsocentrals. Dorsocentrals weak, numerous, unito irregularly tri-serial, beginning above parapsidal suture, setae slightly longer than acrostichals. Prealars uniserial to bi-serial. Supraalars absent, exceptionally 1. Scutellum with numerous weak setae, bi- to tri-serial. Alveoli of all thoracic setae not surrounded by circles lighter in color than adjacent surfaces.

Wing. Costa weakly extended, ending proximal to wing apex. $\mathrm{R}_{2+3}$ ending at one third of the distance between apices of $\mathrm{R}_{1}$ and $\mathrm{R}_{4+5}$. FCu slightly proximal to RM. Brachiolum with 2-3 setae; costal extension with few non-marginal setae; $\mathrm{R}_{4+5}$ occasionally with single seta apically; other veins and membrane bare. Squama with numerous, partly bito tri-serial setae.

Legs. Fore tibia with single, dark comb, with central protruding long spur; mid- and hind tibia with two triangular combs, each with protruding central spur. Fore tarsal beard absent. Pseudospurs absent. Sensilla chaetica present in proximal $1 / 3$ of ta ${ }_{1}$ of mid- and hind leg. Pulvillus pad-like, ventrally covered with elongate trichia, broadly triangular, shorter than empodium, reaching beyond tip of fifth tarsomere to about mid-length of claw.

Hypopygium. Anal point tapering to apex that is tongue-shaped in dorsal view, subacute and slightly curving ventrad in lateral view, without microtrichia except at base. Tergite IX with several weak setae to each side of the base of anal point. Phallapodeme well developed, aedeagal lobe with narrow, 
curved oral projection. Transverse sternapodeme narrow, strongly arched, with low, rounded orolateral projections. Pars ventralis absent. Median volsella composed of elongate, digitiform main stem, split in apical $2 / 3$, projecting posteromedially, densely covered with more or less subulate setae, and with cluster of additional, long subulate setae arising from gonocoxite next to proximal corner of volsella. Superior volsella distally sclerotized, darker than surrounding structures, projecting caudad, not reaching past anal point or distal end of gonocoxite, with broadly triangular base with 1-2 dorsolateral setae, and hooked apical part with few mesally directed setae, without microtrichia on dorsal surface. Inferior volsella broadly digitiform in dorsal view, with microtrichia and normal to strong setae along entire medial length, on distal-dorsal surface and less densely distolaterally; proximoventrally with globose, more membranous expansion. Gonocoxite with 4 ventromedial setae proximal and 3 distal to median volsella. Gonostylus weakly curved with bluntly rounded apex, with row of short, curved setae along inner margin.

\section{Adult female}

As male except antenna with 6 flagellomeres; AR about 0.6 ; flagellomeres $1-5$ each with submedial whorl of 3-5 strong setae and with subapical ring of 2-4 sensilla chaetica; flagellomere 6 with 15-20 sensilla chaetica in apical 3/4. Dorsomedial eye extension less distinct than in male, about 1.2 times as wide as high, mostly of 5-6 facets per diagonal; eyes separated by more than three times the width of the eye extension. Wing veins darker brown than in male, with dark spot along crossvein $\mathrm{RM}$ and radial fork; membrane brown with stronger shading along veins. Wing vein $R_{2+3}$ ending about half-way between apices of $R_{1}$ and $R_{4+5}$.

Abdomen. Tergites I, II, IV-VIII with successively increasing numbers of widely scattered, relatively short but strong setae arising in light-colored circles; tergite III with setae mostly concentrated anteriorly and posteriorly and few setae in between. Paratergites IV (except anteriorly) -VII with conspicuous longitudinal setation. Sternites II-V with (postero)lateral longitudinal rows or patches of setae, sternites VI-VII with these patches spreading to medial and anterior; in addition, sternites VIVII with marginal rows of setae paralleling those on paratergites; sternite VII with posteromedial triangular field of more densely set setae.

Genitalia. Sternite VIII with very dense posteromedial to posterolateral field of setae; zone of transition from sternite to genital bay densely covered with medially directed trichia of various sizes, some arising from papillar but non-alveolar bases; posterior margin of sternite VIII on either side of genital bay with a more or less distinct peak to posterior. Vaginal floor conspicuous in ventral view as a pair of darkened, anteromedially narrowly fused areas; anterior and lateral margin of floor with narrow sclerotization that is posteriorly connected to the gonocoxapodeme VIII; dorsal (intra-vaginal) surface of floor with loosely spaced microtrichia. Gonocoxapodeme VIII nearly straight, extending from dorsal of anteromedial margin of floor to near posteromedial peak of sternite VIII, hardly reaching farther lateral than coxosternapodeme. Gonapophysis VIII with closely adjacent, indistinctly separable lobes. Dorsomesal lobe anteriorly parallel to inner margin of floor with greatest width near posterior end. Ventrolateral lobe arising anteromedial of posteromedial peak of sternite VIII, apparently consisting of two membranous lobes with microtrichia and fine dissections along its medial margin. Apodeme lobe with conspicuous transverse apodeme dorsal of posterior end of dorsomesal lobe, and with extensive soft membrane to medial and posterior that carries many trichia and fine striations on its margin and at least anteroventral surface. Notum extending through most of length of segment VIII, much longer than seminal capsule, free rami very short or indistinct. Seminal capsule ovoid, spermathecal duct nearly straight, carrying secretory cells, subapically narrowing, the two ducts meeting at their joint opening. Coxosternapodeme with extensive anterolateral part carrying a diagonal dorsal ridge, and with narrow anteromedial and posterior extensions. Labium with diagonal internal apodeme and fine to spinose chaetulae on dorsomedial surface.

Tergite IX shallowly hemispherical, with setae indistinctly separated in two groups, and with a posteromedial brown streak that leads towards a sclerotized external tubercle. Gonocoxite IX with dorsal, lateral and ventral setae. Segment X without setae, ventrally with large triangular postgenital plate, dorsally with even longer mediocaudal projection. Cercus long with anterior end curving to lateral where it is fused to segment X.

\section{Systematics}

The new genus is similar to the other genera of the tribe Psudochironomini in having a black comb on the apex of the fore tibia, similar to the combs on mid- and hind tibiae. The males of the genera Manoa, Pseudochironomus and Riethia all lack an anal point, while Aedokritus has a triangular anal point covered with microtrichia at least in basal one half, and Megacentron erebus (Skuse, 
1889) has a rather narrow, spatulate anal point apparently without microtrichia except at base. The male of the new genus has a strong, moderately long, nearly parallel-sided anal point with broadly rounded apex, without microtrichia except at base. It also has a has a digitiform, apically split median volsella with strong brush-like setae, projecting medially, while both Aedokritus and Megacentron have median volsellae projecting caudally. The female genitalia are complex, differing quite strongly from the genitalia of Pseudochironomus and Manoa as described by Sæther (1977a), particularly in the shape of gonapophysis VIII.

\section{Madachironomus lakazana sp. n.}

http://zoobank.org/C8B38DA0-E7ED-45FF8322-BB82A3279AA5

Type material. Holotype male, Madagascar, Antananarivo province, Analamanga region, Anjozorobe district, Anjafy high plains, Betsiboka drainage, Lakazana River at Ankondondona, approx. $47^{\circ} 46^{\prime} \mathrm{E} 18^{\circ} 05^{\prime} \mathrm{S}$, evening of 20.xi.1996, light trap, leg. LRSAE/ORSTOM (ZSM). Paratypes: 1 male, 2 females, same data as holotype (ZMBN, ZSM).

Etymology. Named after Lakazana River, Antananarivo province, Madagascar, where the species was collected. The name is to be regarded as a noun in apposition.

Diagnostic characters. See diagnostic characters for the genus. The female can be separated from the female of $M$. rongaronga $\mathrm{sp}$. $\mathrm{n}$. as it is larger, with a wing length of 4.16-4.18 mm compared to $3.11-3.58 \mathrm{~mm}$ in $M$. rongaronga, has a slightly lower antennal ratio $(\mathrm{AR}=0.58-0.66$ compared to $\mathrm{AR}=0.70-0.81)$ and has distinctly more setae on segment $X$ to each side of vagina (189-231 setae compared to 53-78 setae).

\section{Description}

Adult male ( $\mathrm{n}=2-3)$. Total length 9.16-9.45 mm. Wing length 4.12-4.16 mm. Total length / wing length 2.23-2.27. Wing length / length of profemur 2.32-2.35.

Coloration. Head, antennae and palpi brown. Thorax mostly brown with lateral mesonotal dark brown spot. Legs medium brown, foreleg with tibia and $\mathrm{ta}_{2-5}$ brown, fore tibia with dark brown apex, fore ta ${ }_{1}$ lighter brown with dark brown apex; mid- and hind legs with lighter brown tarsi. Wing membrane (Fig. 8) translucent with brownish stain and some light shaded areas e.g. proximally and distally in cell c, along most of sc, proximal in $\mathrm{r}_{4+5}$ and along $\mathrm{Cu}$ and proximal parts of $\mathrm{M}_{3+4}$ and
$\mathrm{Cu}_{1}$; wing veins brownish, crossvein $\mathrm{RM}$ and radial fork darker brown. Abdominal segment 1 pale brown, abdominal segments 2-5 light brown with narrow anterior transverse brown band; segments 6-8 and hypopygium brown.

Antenna. AR 2.37-2.49. Terminal flagellomere 1503-1560 $\mu \mathrm{m}$ long.

Head (Fig. 1). Temporal setae 22-25, briefly bi- to tri-serial near transition of eye to its dorsomedial extension, consisting of inseparably intergrading verticals and postorbitals. Clypeus with 62-68 setae. Tentorium, stipes and cibarial pump as in Figure 2. Tentorium 277-312 $\mu \mathrm{m}$ long, 82-90 $\mu \mathrm{m}$ wide. Stipes 242-267 $\mu \mathrm{m}$ long, 21-25 $\mu \mathrm{m}$ wide. Palpomere lengths (in $\mu \mathrm{m}$ ): 76-92, 112-128, 396$412,380-384,640-651$. Third palpomere with 2-3 sensilla clavata apically, longest 19-25 $\mu \mathrm{m}$ long.

Thorax (Fig. 3). Antepronotum with 4-6 dorsal and 15-17 ventrolateral setae. Acrostichals apparently about 40; dorsocentrals 42-45, weak; prealars 3-11; supraalars $0-1$. Scutellum with 48-52 setae in 2-3 irregular rows.

Wing (Fig. 8). VR 0.98-0.99. C extension 72-109 $\mu \mathrm{m}$ long. Brachiolum with $2-3$ setae; $\mathrm{C}$ extension with 4-6 non-marginal setae; $\mathrm{R}_{4+5}$ with $0-1$ seta apically; other veins bare. Wing membrane bare. Squama with 28-36 setae, partly bi- to tri-serial.

Legs (Figs 4-5). Spur of fore tibia 80-89 $\mu \mathrm{m}$ long; spurs of mid tibia 100-115 $\mu \mathrm{m}$ and 103-121 $\mu \mathrm{m}$ long; spurs of hind tibia 105-121 $\mu \mathrm{m}$ and 113-127 $\mu \mathrm{m}$ long. Width at apex of fore tibia $111-113 \mu \mathrm{m}$; of mid tibia 127-131 $\mu \mathrm{m}$; of hind tibia 135-139 $\mu \mathrm{m}$. Mid ta $\mathrm{ta}_{1}$ with about 15 sensilla chaetica in 3 rows in proximal $1 / 3$, hind ta ${ }_{1}$ with about 25 sensilla chaetica in 3 rows in proximal $1 / 3$. Lengths and proportions of legs as in Table 1.

Hypopygium (Figs 6-7). Tergite IX with 13-17 setae along posterior margin to each side of base of anal point; laterosternite IX with 15-23 setae. Anal point tapering to tongue-shaped apex, 115-123 $\mu \mathrm{m}$ long, 66-75 $\mu \mathrm{m}$ wide at base, $29-35 \mu \mathrm{m}$ wide subapically. Phallapodeme 316-324 $\mu \mathrm{m}$ long, including 88-96 $\mu \mathrm{m}$ long, 8-12 $\mu \mathrm{m}$ wide, curved oral projection. Transverse sternapodeme 120-128 $\mu \mathrm{m}$ long. Gonocoxite 380-404 $\mu \mathrm{m}$ long. Median volsella with main stem split medially in two digitiform projections; longest, caudal branch 72-80 $\mu \mathrm{m}$ long, 16-20 $\mu \mathrm{m}$ wide medially; shortest, oral branch 66-84 $\mu \mathrm{m}$ long; densely covered with subulate setae up to $66-85 \mu \mathrm{m}$ in length. Superior volsella 92-108 $\mu \mathrm{m}$ long, including 34-38 $\mu \mathrm{m}$ long, hooked apical portion; with 1-2 strong, 28-30 $\mu \mathrm{m}$ long setae dorsolaterally, hooked apical portion 


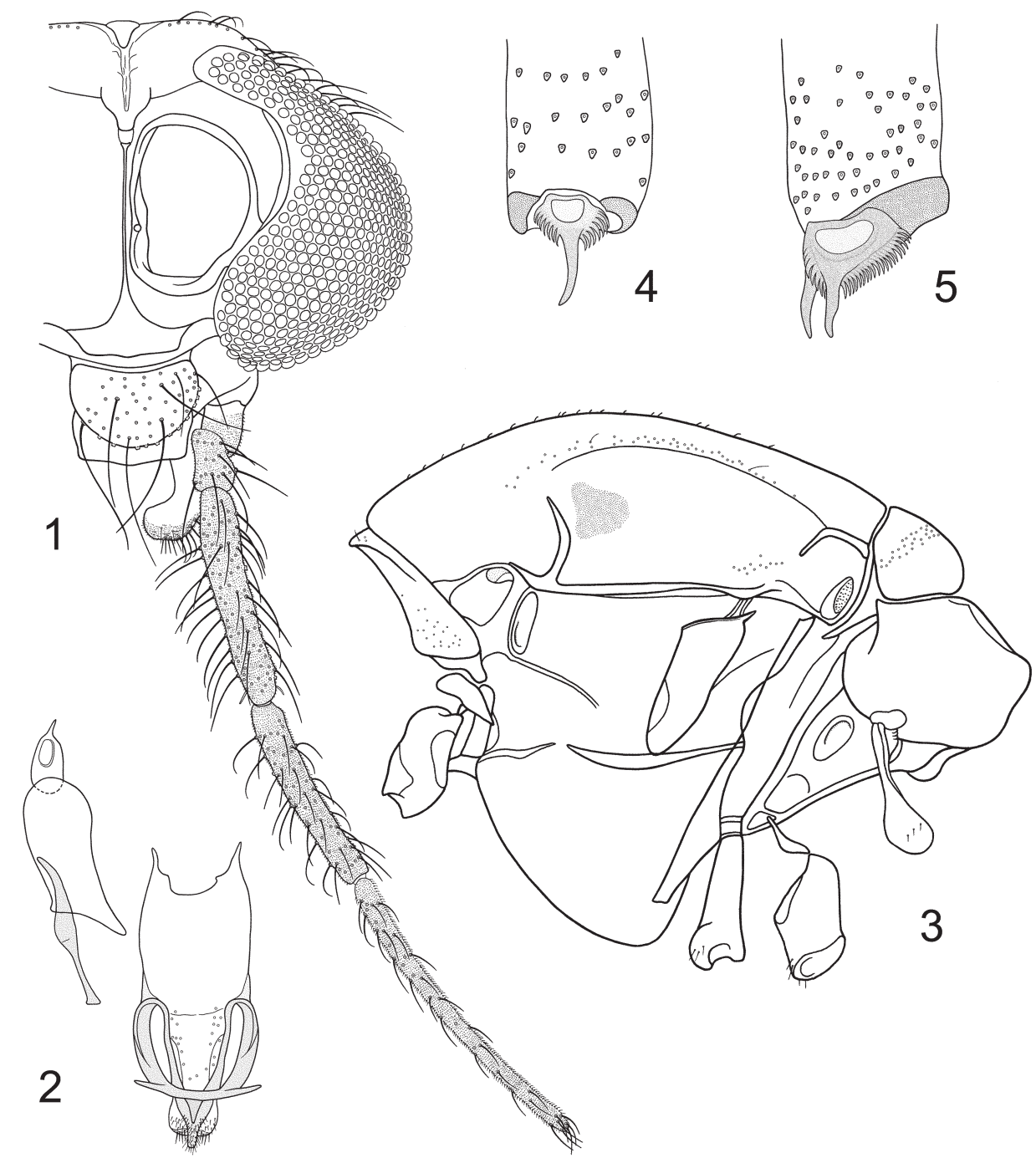

Figures 1-5. Madachironomus lakazana gen. n., sp. n., male. 1) head; 2) tentorium, stipes and cibarial pump; 3) thorax; 4) comb of foreleg; 5) combs of hind leg.

Table 1. Lengths (in $\mu \mathrm{m}$ ) and proportions of legs of Madachironomus lakazana gen. n., sp. n., male ( $\mathrm{n}=2-3$ ).

\begin{tabular}{ccccccc}
\hline & $\mathbf{f e}$ & $\mathbf{t i}$ & $\mathbf{t a}_{1}$ & $\mathbf{t a}_{\mathbf{2}}$ & $\mathbf{t a}_{\mathbf{3}}$ & $\mathbf{t a}_{4}$ \\
\hline $\mathbf{p}_{\mathbf{1}}$ & $1730-1812$ & $2368-2410$ & $1854-1957$ & $741-824$ & $597-698$ & $494-556$ \\
$\mathbf{p}_{\mathbf{2}}$ & $2266-2307$ & $2575-2657$ & $1009-1092$ & $556-577$ & $494-536$ & $309-330$ \\
$\mathbf{p}_{\mathbf{3}}$ & $2369-2410$ & $2822-2843$ & $1215-1318$ & $638-701$ & $577-639$ & $330-391$ \\
\hline & $\mathbf{t a}$ & $\mathbf{L R}$ & $\mathbf{B V}$ & $\mathbf{S V}$ & $\mathbf{B R}$ \\
\hline $\mathbf{p}_{\mathbf{1}}$ & $206-247$ & $0.769-0.826$ & $2.661-2.949$ & $2.137-2.244$ & $1.813-1.866$ \\
$\mathbf{p}_{\mathbf{2}}$ & $144-165$ & $0.380-0.424$ & $3.753-3.959$ & $4.434-4.898$ & $2.125-2.166$ \\
$\mathbf{p}_{\mathbf{3}}$ & $154-165$ & $0.431-0.467$ & $3.467-3.747$ & $3.938-4.271$ & $2.211-2.500$ \\
\hline
\end{tabular}

with 3-6 medial to ventral setae. Inferior volsella broadly digitiform, 208-212 $\mu \mathrm{m}$ long, 80-100 $\mu \mathrm{m}$ wide at base, $48-56 \mu \mathrm{m}$ wide medially, with $63-82$ normal to strong setae. Gonostylus $328-344 \mu \mathrm{m}$ long. HR 1.11-1.20. HV 2.74-2.80.

Adult female $(\mathrm{n}=2)$. Total length $9.83-9.93 \mathrm{~mm}$. Wing length 4.16-4.18 mm. Total length / wing length 2.36-2.39. Wing length / length of profe- mur 2.39-2.43.

Coloration. Generally distinctly darker than male. Head, antennae and palpi brown. Thorax mostly brown, lateral mesonotal dark spot less contrasting than in male, indistinct in some specimens. Legs medium brown; foreleg with tibia and $\mathrm{ta}_{2-5}$ darker brown, fore tibia with dark brown apex, fore ta lighter brown with dark brown apex; mid- and 


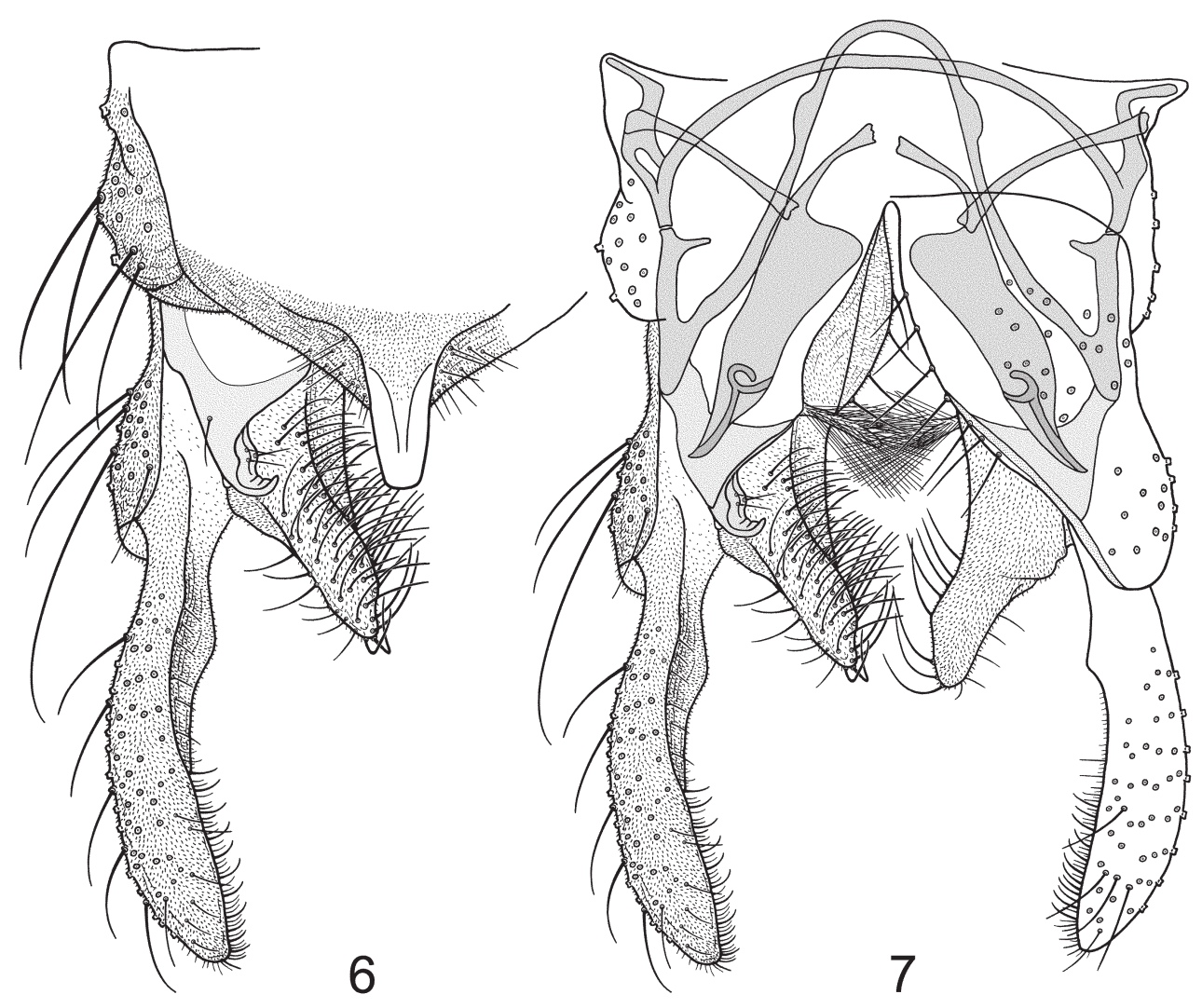

Figures 6-7. Madachironomus lakazana gen. n., sp. n., male. 6) hypopygium, dorsal view; 7) hypopygium with anal point and tergite IX removed, dorsal aspect to the left and ventral aspect to the right.

hind legs with lighter brown femoral apices and tarsi. Wing membrane translucent with brownish stain and some more darkly shaded areas, e.g. proximally and distally in cell c, along most of sc, proximally in $\mathrm{r}_{1}$ and $\mathrm{r}_{4+5}$, along $\mathrm{Cu}$ and proximal parts of $\mathrm{M}_{3+4}$ and $\mathrm{Cu}_{1}$; veins brown, crossvein $\mathrm{RM}$ and radial fork darker brown. Abdominal tergites and posterior sternites brown, anterior sternites light brown, anterior transverse segment bands indicated in some specimens; hypopygium medium brown.

Antenna (Fig. 12). With 6 flagellomeres; AR $=0.58-0.66$. Length and width of pedicel and flagellomeres 1-6 (in $\mu \mathrm{m}$ ) as: 80-92 / 128-132, 100-104 / 56-60, 84-88 / 40-44, 92-104 / 40-44, 96-104 / 38-42, 88-92 / 36-40, 272-300 / 28-32. Flagellomeres $1-5$ with ring of sensilla chaetica subapically, flagellomere 6 with sensilla chaetica in apical 2/3. Flagellomere 6 with 1-2 strong setae subapically, longest 118-148, $133 \mu \mathrm{m}$ long.

Head (Fig. 10). Temporal setae 22-24, briefly bi- to tri-serial near transition of eye to its dorsomedial extension, consisting of inseparably intergrading verticals and postorbitals. Clypeus with 105-112 setae. Tentorium, stipes and cibarial pump as in Figure 11. Tentorium 304-316 $\mu \mathrm{m}$ long, 76-80 $\mu \mathrm{m}$ wide. Stipes 272-312 $\mu \mathrm{m}$ long, 24-28 $\mu \mathrm{m}$ wide. Palp segment lengths (in $\mu \mathrm{m}$ ): 87-98, 108-114, 376-380, 380-388, 556-588. Third palpomere with 2-3 sensilla clavata apically, longest 21-25 $\mu \mathrm{m}$ long.

Thorax (Fig. 13). Antepronotum with 6-9 dorsal and 14-15 ventrolateral setae. Acrostichals apparently about 40; dorsocentrals 36-41 weak, in 1-3 irregular rows; prealars 7-8. Scutellum with 44-48 setae in $2-3$ rows.

Wing. VR 1.01-1.07. C extension about $60 \mu \mathrm{m}$ long. Brachiolum with 2 setae, $\mathrm{C}$ extension with 2-5 non-marginal setae, $\mathrm{R}_{1}$ with 8-12 setae in apical $1 / 3, \mathrm{R}_{4+5}$ with $2-5$ seta apically, other veins bare. Wing membrane bare. Squama with 31-35 setae, partly bi- to triserial. 


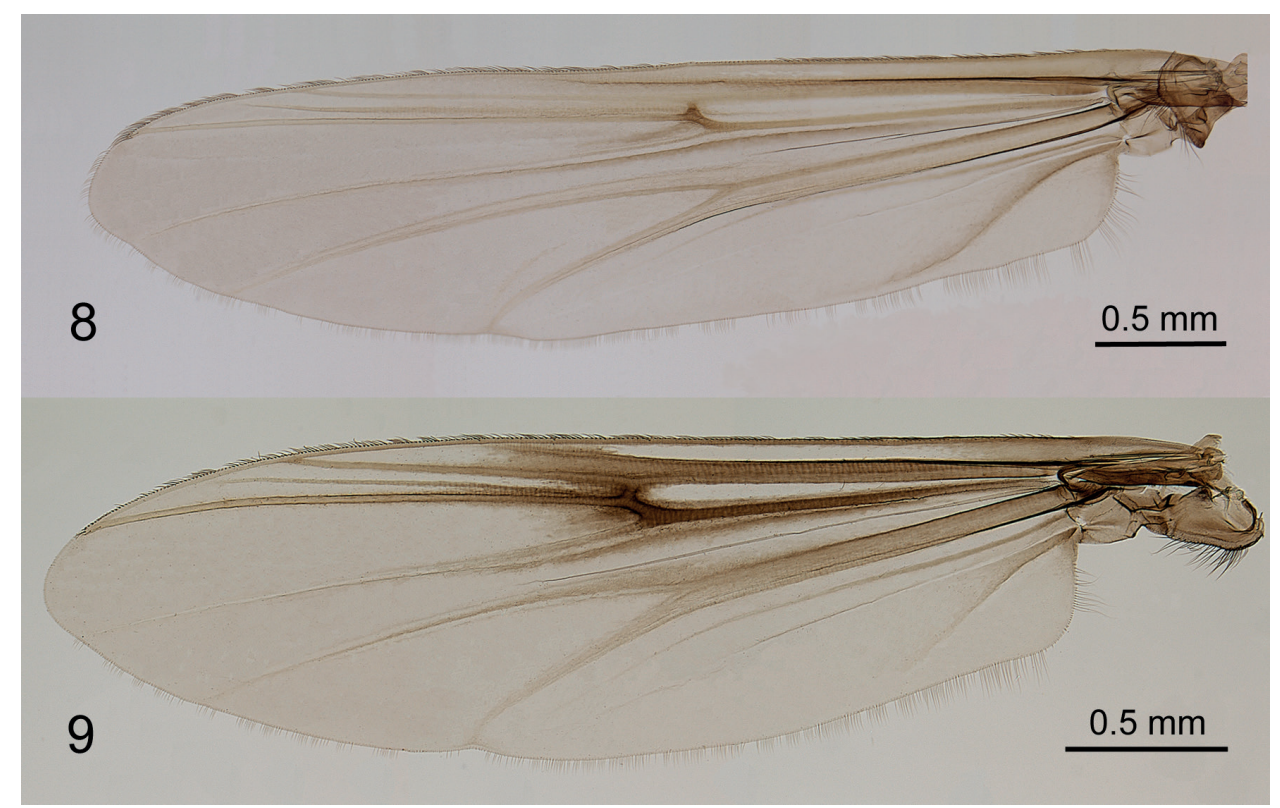

Figures 8-9. Madachironomus gen. n., wings. 8) M. lakazana sp. n., male; 9) M. rongaronga sp. n., female (photo Torbjørn Ekrem).

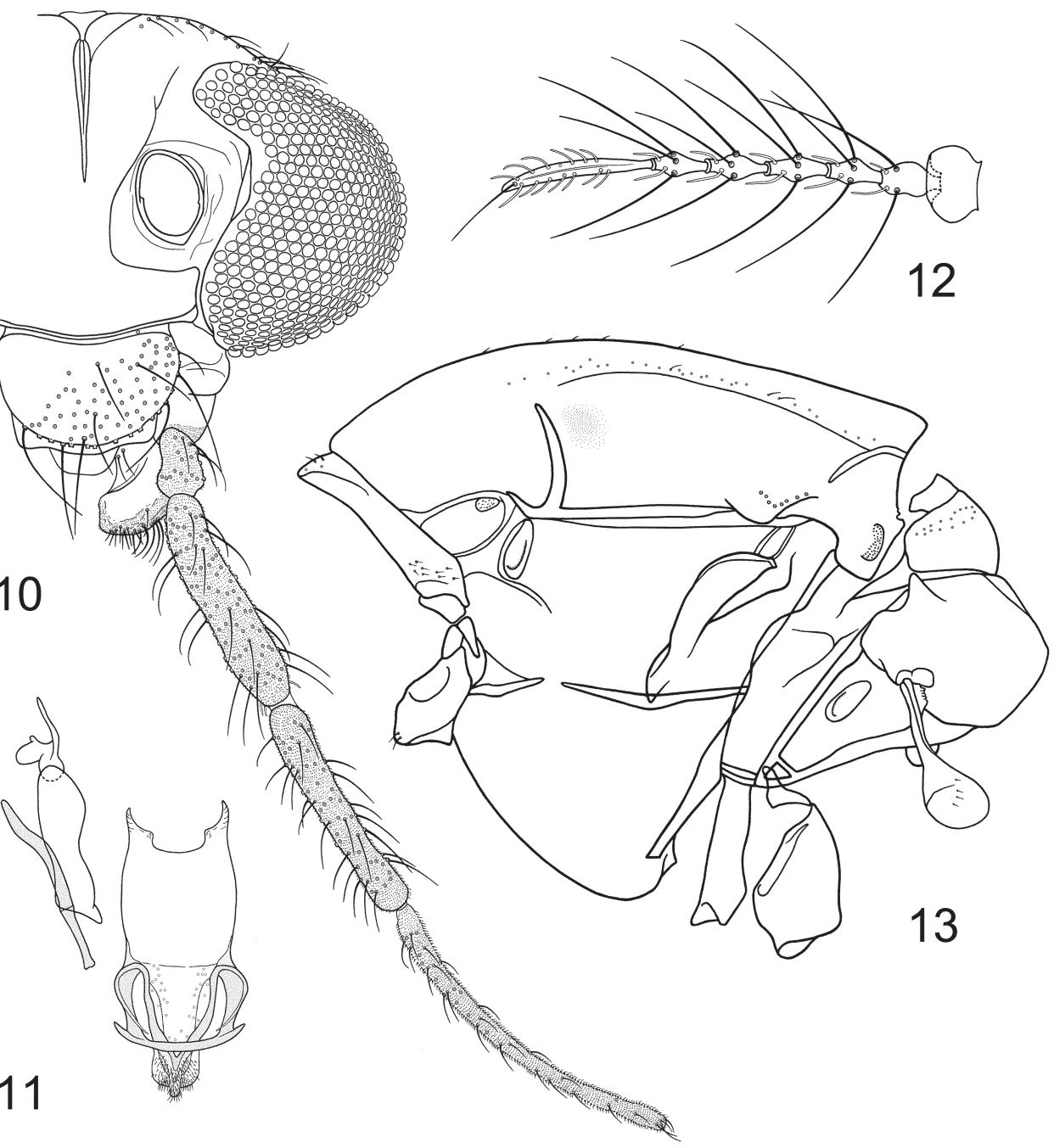

Figures 10-13. Madachironomus lakazana gen. n., sp. n., female. 10) head; 11) tentorium, stipes and cibarial pump; 12) antenna; 13) thorax. 


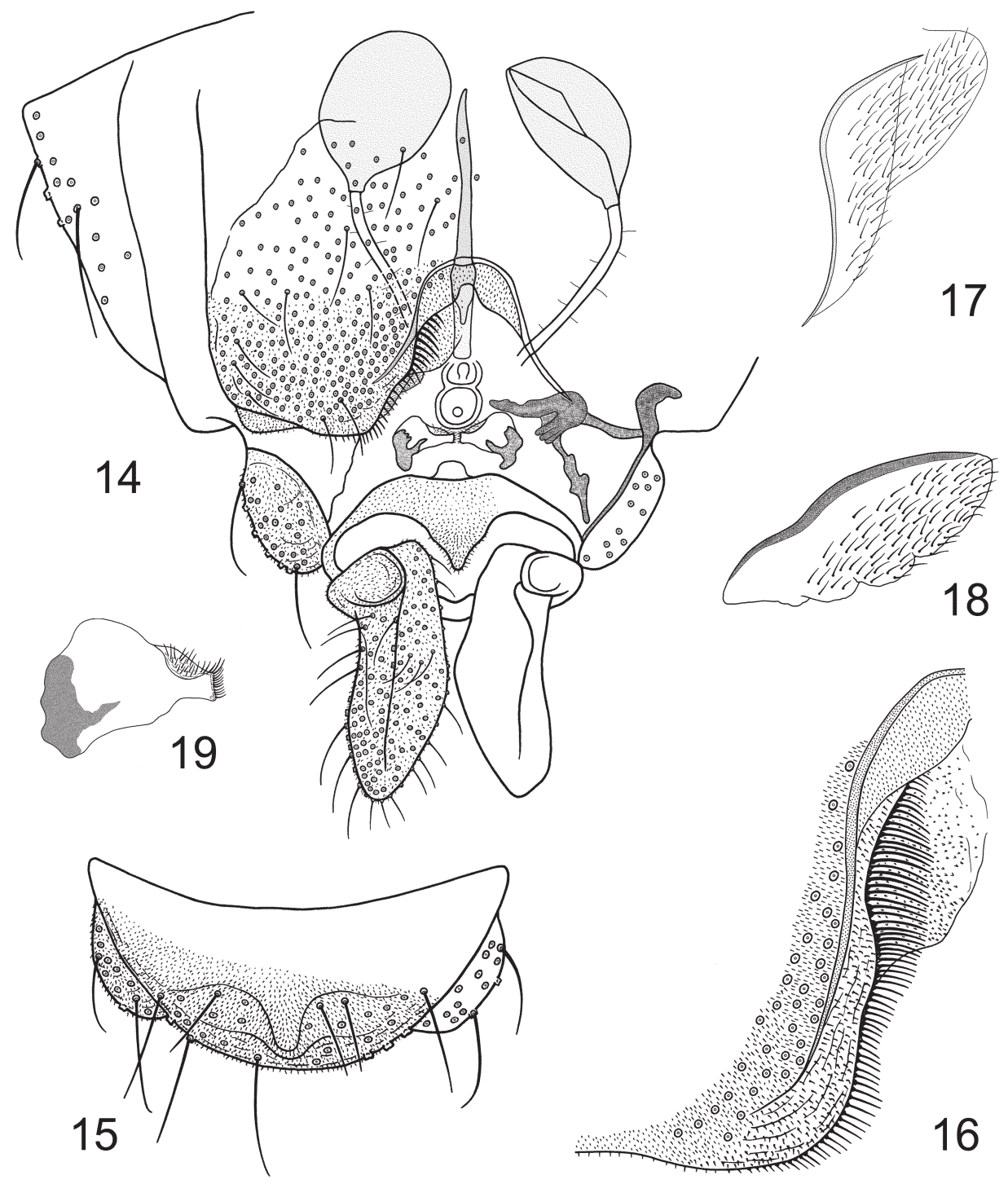

Figures 14-19. Madachironomus lakazana gen. n., sp. n., female. 14) genitalia, ventral view; 15) tergite IX; 16) dorsomesal lobe; 17) ventrolateral lobe; 18) apodeme lobe; 19) labium.

Table 2. Lengths (in $\mu \mathrm{m}$ ) and proportions of legs of Madachironomus lakazana gen. n., sp. n., female $(\mathrm{n}=2)$.

\begin{tabular}{|c|c|c|c|c|c|c|}
\hline & fe & ti & $\mathrm{ta}_{1}$ & $\mathrm{ta}_{2}$ & $\mathrm{ta}_{3}$ & $\mathrm{ta}_{4}$ \\
\hline $\mathbf{p}_{1}$ & $1710-1751$ & $2348-2410$ & $1710-1812$ & $700-721$ & $618-639$ & $494-515$ \\
\hline $\mathbf{p}_{2}$ & $2245-2266$ & 2554-2698 & 948-1009 & $515-556$ & $453-474$ & $288-330$ \\
\hline $\mathbf{p}_{3}$ & 2369-2390 & 2760-2946 & $1195-1257$ & $597-700$ & $556-618$ & $350-371$ \\
\hline & $\mathrm{ta}_{5}$ & \multicolumn{2}{|c|}{ LR } & BV & SV & BR \\
\hline $\mathbf{p}_{1}$ & $226-247$ & \multicolumn{2}{|c|}{$0.728-0.752$} & $2.800-2.843$ & $2.295-2.373$ & $1.733-1.750$ \\
\hline$p_{2}$ & $144-165$ & \multicolumn{2}{|c|}{$0.371-0.374$} & $3.905-4.118$ & $4.898-5.087$ & $1.750-1.888$ \\
\hline$p_{3}$ & $144-165$ & \multicolumn{2}{|c|}{$0.427-0.433$} & $.556-3.837$ & $4.293-4.246$ & $1.600-1.700$ \\
\hline
\end{tabular}

Legs. Spur of fore tibia 76-80 $\mu \mathrm{m}$ long, spurs of mid tibia 100-104 $\mu \mathrm{m}$ and 112-116 $\mu \mathrm{m}$ long, of hind tibia 100-108 $\mu \mathrm{m}$ and 116-120 $\mu \mathrm{m}$ long. Width at apex of fore tibia 116-124 $\mu \mathrm{m}$, of mid tibia 128-136 $\mu \mathrm{m}$, of hind tibia 136-144 $\mu \mathrm{m}$. Mid $\mathrm{ta}_{1}$ with about 50 sensilla chaetica in 2-3 rows in proximal $1 / 3$, hind ta with about 35 sensilla chaetica in $2-3$ rows in proximal $1 / 3$. Lengths and proportions of legs as in Table 2.

Genitalia (Figs 14-19). Segment X with 189-231 setae to each side of vagina. Seminal capsule ovoid, 176-184 $\mu \mathrm{m}$ long, not including 18-20 $\mu \mathrm{m}$ 
long neck, 120-132 $\mu \mathrm{m}$ wide. Notum 204-228 $\mu \mathrm{m}$ long. Dorsomesal lobe 218-224 $\mu \mathrm{m}$ long from base of vagina to apex. Gonocoxite IX with 28-30 setae. Tergite IX with 31-37 setae. Cercus 284$292 \mu \mathrm{m}$ long.

Larva and pupa. Unknown.

\section{Madachironomus rongaronga sp. $\mathbf{n}$.}

http://zoobank.org/378E3CFF-4AF5-408A-956AOC99A71F295B

Type material. Holotype female, Madagascar, Toamasina province, Atsinanana region, Vohibinany district; Rianila drainage, Rongaronga River at Ambinaninony-Sahavalaina, approx. 49 $07^{\prime} \mathrm{E}$ $18^{\circ} 34^{\prime}$ S, evening of 19.ix.1995, light trap, leg. LRSAE/ORSTOM (ZSM). Paratypes: 3 females, same data as holotype (ZMBN, ZSM).

Etymology. Named after Rongaronga River, Toamasina province, Madagascar, where the species was collected. The name is to be regarded as a noun in apposition.

Diagnostic characters. See diagnostic characters for M. lakazana sp. n.

\section{Description}

Adult female $(\mathrm{n}=4)$. Total length 7.07-7.83, $7.49 \mathrm{~mm}$. Wing length $3.11-3.58,3.28 \mathrm{~mm}$. Total length / wing length $2.08-2.45,2.26$. Wing length / length of profemur 2.22-2.43, 2.35.

Coloration. Head, antennae and palpi brown. Thorax mostly brown, without lateral mesonotal dark spot. Legs brown; foreleg with lighter brown ta mid- and hind legs with lighter brown tarsi. Wing membrane (Fig. 9) translucent with brownish stain and more darkly shaded areas, e.g. proximally and distally in cell c, along most of sc, proximally in $r_{1}$ and $\mathrm{r}_{4+5}$, along $\mathrm{Cu}$ and proximal parts of $\mathrm{M}_{3+4}$ and $\mathrm{Cu}_{1}$; veins brown, crossvein $\mathrm{RM}$ and radial fork darker brown. Abdomen and hypopygium brown, first abdominal segment lighter brown.

Antenna. With 6 flagellomeres; AR $=0.70-0.81$, 0.78 . Length and width of pedicel and flagellomeres 1-6 (in $\mu \mathrm{m}$ ) as: 72-84, 80 / 112-120, 117; 80-
88,85 / 44-48, 46; 60-64, 61 / 34-40, 36; 68-80, 72 / 32-40, 36; 64-76, 71 / 32-38, 36; 64-80, 74 / 32-36, 34; 276-296, 288 / 24-30, 28. Flagellomeres $1-5$ with ring of sensilla chaetica subapically, flagellomere 6 with sensilla chaetica in apical 3/4. Flagellomere 6 with 1-2 strong setae subapically, longest 121-160, $138 \mu \mathrm{m}$ long.

Head. Temporal setae 14-18, 16, briefly bi-serial near transition of eye to its dorsomedial extension, consisting of inseparably intergrading verticals and postorbitals. Clypeus with 79-108, 93 setae. Tentorium 180-256, $220 \mu \mathrm{m}$ long; 56-64, $61 \mu \mathrm{m}$ wide. Stipes 220-240, $230 \mu \mathrm{m}$ long; 18-23, 21 $\mu \mathrm{m}$ wide. Palp segment lengths (in $\mu \mathrm{m}$ ): $80-88$, 85 ; 92-112, 99; 332-420, 362; 356-436, 389; 560-648, 590. Third palpomere with 1-2 sensilla clavata apically, longest 17-22 $\mu \mathrm{m}$ long.

Thorax. Antepronotum with 4-7, 5 dorsal and 7-12, 10 ventrolateral setae. Acrostichals apparently about 35; dorsocentrals 24-34, 30 weak, in 1-2 irregular rows; prealars 4-6, 5. Scutellum with $41-44,42$ setae in 2-3 rows.

Wing (Fig. 9). VR 0.94-1.00, 0.97. C extension 47-75, $65 \mu \mathrm{m}$ long. Brachiolum with 2-3, 2 setae; C extension with 2-4, 3 non-marginal setae; $\mathrm{R}_{1}$ with 5-14, 11 setae in apical $1 / 3 ; \mathrm{R}_{4+5}$ with $1-3$, 2 setae apically; other veins bare. Wing membrane bare. Squama with $27-33,31$ setae, partly bi- to tri-serial.

Legs. Spur of fore tibia 60-64, $62 \mu \mathrm{m}$ long; spurs of mid tibia 68-84 (3) $\mu \mathrm{m}$ and 80-100, $94 \mu \mathrm{m}$ long; of hind tibia 80-96, $90 \mu \mathrm{m}$ and 96-108, 103 $\mu \mathrm{m}$ long. Width at apex of fore tibia 96-100, 99 $\mu \mathrm{m}$; of mid tibia 100-108, $104 \mu \mathrm{m}$; of hind tibia 104-116, $113 \mu \mathrm{m}$. Mid ta ${ }_{1}$ with about 35 sensilla chaetica in 2-3 rows in proximal $1 / 3$, hind ta ${ }_{1}$ with about 40 sensilla chaetica in $2-3$ rows in proximal 1/3. Lengths and proportions of legs as in Table 3.

Genitalia (Figs 20-25). Segment X with 53-78, 63 setae to each side of vagina. Tergite IX with $22-$ 28, 24 setae. Seminal capsule ovoid, 133 (1) $\mu \mathrm{m}$ long, not including 31 (1) $\mu \mathrm{m}$ long neck, 121 (1) $\mu \mathrm{m}$ wide. Notum 184-193 (3) $\mu \mathrm{m}$ long. Dorsome-

Table 3. Lengths (in $\mu \mathrm{m}$ ) and proportions of legs of Madachironomus rongaronga gen. n., sp. n., female ( $\mathrm{n}=3$, except when otherwise stated).

\begin{tabular}{ccccccc}
\hline & $\mathbf{f e}$ & $\mathbf{t i}$ & $\mathbf{t a}_{1}$ & $\mathbf{t a}_{\mathbf{2}}$ & $\mathbf{t a}_{3}$ & $\mathbf{t a}_{4}$ \\
\hline $\mathbf{p}_{\mathbf{1}}$ & $1318-1524$ & $1772-2081$ & $1318-1483$ & $618-701$ & $536-577$ & $433-474$ \\
$\mathbf{p}_{\mathbf{2}}$ & $1751-2019$ & $2225-2534$ & $803-927$ & $433-494$ & $350-391$ & $206-247$ \\
$\mathbf{p}_{\mathbf{3}}$ & $1895-2163$ & $2431-2699$ & $1009-1154$ & $536-618$ & $433-474$ & $247-288$ \\
\hline & $\mathbf{t a}_{5}$ & $\mathbf{L R}$ & & $\mathbf{B V}$ & $\mathbf{S V}$ & $\mathbf{B R}$ \\
\hline $\mathbf{p}_{\mathbf{1}}$ & $196-227$ & $0.970-1.000$ & $2.446-2.573$ & $2.344-2.453$ & $1.471(1)$ \\
$\mathbf{p}_{\mathbf{2}}$ & $103-124$ & $0.358-0.366$ & $4.315-4.434$ & $4.911-5.026$ & $1.643(1)$ \\
$\mathbf{p}_{\mathbf{3}}$ & $103-124$ & $0.415-0.427$ & $3.912-4.047$ & $4.214-4.286$ & $2.125-2.500$ \\
\hline
\end{tabular}




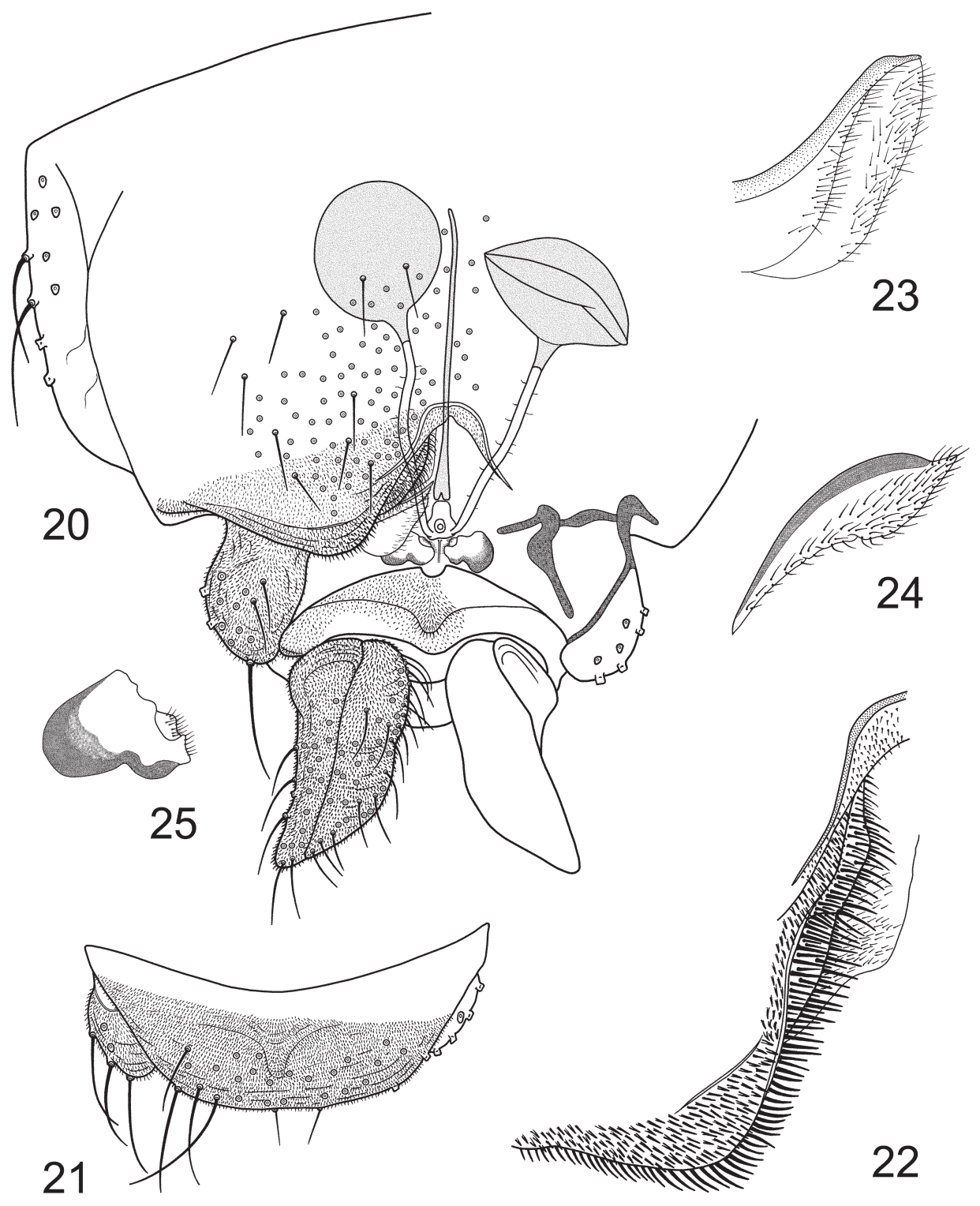

Figures 20-25. Madachironomus rongaronga gen. n., sp. n., female. 20) genitalia, ventral view; 21) tergite IX; 22) dorsomesal lobe; 23) ventrolateral lobe; 24) apodeme lobe; 25) labium.

sal lobe $156-176,165 \mu \mathrm{m}$ long from base of vagina to apex. Gonocoxite IX with 16-23, 18 setae. Tergite IX with 21-27, 24 setae. Cercus 208-240, $225 \mu \mathrm{m}$ long.

\section{Adult male, larva and pupa. Unknown.}

\section{Discussion}

Cranston (2003: 184) described Pseudochironomini as "almost certainly a paraphyletic grade", and according to Epler et al. (2013: 433) the "validity and characteristics of a tribe Pseudochironomini are uncertain". As reflected in these statements, considerable evidence needs to be gathered and evaluated before this opinion could become a widely accepted systematic result. In any case, note that these doubts address the relatively wide concept of the tribe drawn up by Sæther (1977a: 154). If Pseudochironomini proves untenable in the traditional sense, the name might still be applied to any monophylum that includes the type genus, Pseudochironomus, but excludes one or more of the other currently included genera, provided that the resulting smaller clade still warrants the status of a tribe. Andersen et al. (2011: 48 ) indicated one such possibility, but also found the available data to be insufficient for a meaningful conclusion. 
Polukonova et al. (2013) analyzed amino acid proportions in the barcoding section of the COI gene from various Chironominae species, and reported the observed divergences among taxa to increase significantly with each higher systematic rank. They proposed that corresponding divergence observed in any pair of species or genera indicates whether or not the two taxa belong to the respective same genus, tribe or subfamily. Applying this to the Chironominae, they found support for the distinction of three major subdivisions, one of these 'tribes' being Tanytarsini in the traditional sense. However, another 'tribe' combined Pseudochironomus ("P. sp." from GenBank; the genus might be misidentified) with Polypedilum Kieffer and Sergentia Kieffer, Endochironomus Kieffer and Synendotendipes Grodhaus, whereas in the third 'tribe' Riethia ("R. stictoptera" from GenBank) clustered with the remainder of Chironomini.

The latter association is fundamentally different from the results of Cranston et al. (2012; Pseudochironomus not included), whose multi-gene analysis had Riethia so far removed from Polukonova et al.'s 'remaining' Chironomini that the two are not even part of the same larger monophylum. However, the two sets of results agree in suggesting that the tribes Chironomini and Pseudochironomini look untenable in their traditional definitions. More research is thus needed to clarify the status of the tribe Pseudochironomini.

\section{Acknowledgements}

I am greatly indebted to Martin Spies for recognizing the new genus and for all input to the manuscript. I am also indebted to Gladys Ramirez for making the slide preparations and to Torbjørn Ekrem for the wing photos. Thanks to two anonymous reviewers for their input on the manuscript.

\section{References}

Andersen, T. and Sæther, O.A. 1997. First record of Manoa Fittkau and the tribe Pseudochironomini Sæther from the Afrotropical region (Diptera: Chironomidae: Chironominae) - Entomologica scandinavica 28: 311-317.

Andersen; T., Sæther, O.A. and Contreras-Ramos, A. 2011. New species and records of Nandeva Wiedenbrug, Reiss et Fittkau (Chironomidae: Chironominae). - Zootaxa 3136: 45-60.

Cranston, P.S. 2003. The oriental genus Shangomyia Sæther \& Wang (Chironomidae: Diptera): immature stages, biology, putative relationships and the evolution of wood mining in chironomid larvae. - The Raffles Museum Bulletin of Zoology 51: 179-186.
Cranston, P.S., Hardy, N.B. and Morse, G.E. 2012. A dated molecular phylogeny for the Chironomidae (Diptera). - Systematic Entomology 37: 172-188. DOI: http://dx.doi.org/10.1111/ j.1365-3113.2011.00603.x

Curran, C.H. 1934. The Templeton Crocker Expedition of the California Academy of Sciences, 1932. No. 13. Diptera. - Proceedings of the California Academy of Sciences, $4^{\text {th }}$ Series 21: 147-172.

Epler, J.H., Ekrem, T. and Cranston, P.S. 2013. 10. The larvae of Chironominae (Diptera: Chironomidae) of the Holarctic region - Keys and diagnoses. In: Andersen, T., Cranston, P.S. \& Epler, J.H. (Eds), Chironomidae of the Holarctic Region: Keys and Diagnoses. Part 1. Larvae. - Insect Systematics and Evolution, Supplement 66: 387-556.

Fittkau, E.J. 1963. Manoa, eine neue Gattung der Chironomidae (Diptera) aus Zentralamazonien. Chironomidenstudien IX. - Archiv fur Hydrobiologie 59: 373-390.

Freeman, P. 1961. The Chironomidae (Diptera) of Australia. - Australian Journal of Zoology 9: 611-737.

Jacobsen, R.E. and Perry, S.A. 2002. A new species of Manoa (Diptera: Chironomidae) from Everglades National Park. - Journal of the North American Benthological Society 21: 314-325.

Kieffer, J.J. 1917. Chironomides d'Australie conserves au Musée National Hongrois de Budapest. - Annales historico-naturales Musei nationalis hungarici 15: 175-228.

Malloch, J.R. 1915. The Chironomidae or midges of Illinois, with particular reference to the species occurring in the Illinois River. - Bulletin of the Illinois State Laboratory of Natural History 10: 275-543.

Polukonova, N.V., Demin, A.G. and Mugue, N.S. 2013. Molecular criteria in insects systematics: Bar-coding gene COI range of variability as a taxonomic criterion for genus, tribe, and subfamily, with Chironominae and Orthocladiinae midges (Chironomidae, Diptera) as a case study. - Zhurnal obshcher biologii 74: 66-76. DOI: http://dx.doi.org/10.1134/ $\underline{\mathrm{S} 0013873814070045}$

Roback, S.S. 1958. Results of the Catherwood Foundation Peruvian Amazon Expedition. A new genus and species of Tendipedini from Peru with some observations on related genera. 
Diptera, Tendipedidae (= Chironomidae). - Notula Naturae 304: 1-5.

Sæther, O.A. 1969. Some Nearctic Podonominae, Diamesinae and Orthocladiinae (Diptera: Chironomidae). - Bulletin of the Fisheries Research Board of Canada 107: 1-154.

Sæther, O.A. 1977a. Female genitalia in Chironomidae and other Nematocera: morphology, phylogenies, keys. - Bulletin of the Fisheries Research Board of Canada 197: 1-204.

Sæther, O.A. 1977b. Taxonomic studies on Chironomidae: Nanocladius, Pseudochironomus and the Harnischia complex. - Bulletin of the Fisheries Research Board of Canada 196: 1-204.

Sæther, O.A. 1980. Glossary of chironomid morphology terminology (Diptera: Chironomidae). - Entomologica scandinavica, Supplement 14: $1-51$.

da Silva, F.L., Wiedenbrug, S. and Farrell, B.D. 2015. A preliminary survey of the non-biting midges (Diptera: Chironomidae) of the Do- minican Republic. - Chironomus Newsletter on Chironomidae Research 28: 12-19. DOI: http://dx.doi.org/10.5324/cjcr.v0i28.1925

Spies, M. and Reiss, F. 1996. Catalog and bibliography of Neotropical and Mexican Chironomidae) (Insecta, Diptera). - Spixiana, Supplement 22: 61-119.

Sublette, J.E. 1966. Type specimens of Chironomidae (Diptera) in the American Museum of natural History. - Journal of the Kansas Entomological Society 39: 1-32.

Trivinho-Strixino, S. 1997. Nova espécie do gênero Aedokritus Roback, 1958 (Diptera, Chironomidae), com descriçao das formas imaturas. Revista Brasileira de Entomologia 41: 13-16.

Trivinho-Strixino, S., Roque, F.O. \& Cranston, P.S. 2009. Redescription of Riethia truncatocaudata (Edwards, 1931) (Diptera: Chironomidae), with description of female, pupa and larva and generic diagnosis for Riethia. - Aquatic Insects 31: 247-259. DOI: http:// dx.doi.org/10.1080/01650420902787556 